\title{
On the rising incidence of early breast development: puberty as an adaptive escape from ectopic adiposity in mismatch girls
}

\author{
Francis de Zegher ${ }^{11}$ and Lourdes Ibáňez ${ }^{2}$ \\ ${ }^{1}$ University of Leuven, Leuven, Belgium and ${ }^{2}$ University of Barcelona, Barcelona, Spain
}

\author{
Correspondence \\ should be addressed \\ to $\mathrm{F}$ de Zegher \\ Email \\ Francis.deZegher@ \\ uzleuven.be
}

Over the past decades, there has been a worldwide trend towards younger ages of pubertal onset in girls (1). Overall, this trend has been estimated at 3 months per decade (1) but some regions are experiencing faster transitions, in parallel with rapid gains in body weight. In Korea, for example, the prevalence of precocious puberty in girls has increased $>10$-fold within a single generation (2). Such alarming rises are not readily attributable to exposures to endocrine disruptors (3) and are still under active investigation.

One of the proposed hypotheses is that an earlier/ faster maturation in girls is the phenotypic expression of an adaptive mechanism whereby girls attempt to escape from ectopic adiposity which, in turn, ensues from a mismatch between reduced prenatal weight gain (with reduced s.c. adipogenesis, thus a reduced capacity for safe lipid storage) and augmented postnatal weight gain (with augmented lipogenesis, and thus an augmented need for lipid storage) (4). This hypothesis builds upon the more general mismatch concept that offers an explanation for a variety of recent trends and emerging phenotypes (5). For example, the mismatch between reduced prenatal weight gain and augmented postnatal weight gain contributes to explain the trends towards higher blood pressures in early childhood (6), towards exaggerated adrenarche (higher concentrations of circulating DHEAS sometimes eliciting a precocious pubarche) (7), towards younger ages at menarche (8), and towards higher incidences of polycystic ovary syndrome (9). In the context of precocious puberty, the presence or absence of such a mismatch can readily be estimated by calculating the upward change in Z-score (or centile) between birthweight-for-gestational-age and
BMI-at-onset-of-puberty $(4,10)$. Hitherto, however, this mismatch hypothesis has remained untested as a potential explanation for the increasing incidence of precocious puberty.

In a recent issue of the European Journal of Endocrinology, Harbulot et al. (11) reported how they performed the first test of the mismatch hypothesis, by analysing their single-centre cohort of girls with isolated variants of central precocious puberty $(n=319)$ in an unprecedented way: they distinguished three subgroups and calculated the Z-scores of birthweight-for-gestationalage and BMI-at-diagnosis-of-central-precocious-puberty in each subgroup. Their findings (Fig. 1) endorse the mismatch concept since the three subgroups ('familial', 'sporadic', and 'adopted') tended to differ in birthweight (average centiles 50, 34, and 10, respectively) and also in BMI-at-diagnosis (centiles 96, 90, and 76), so that the upward changes between birth and puberty amounted on average to 46,56, and 66 centiles. These marked increments are likely to be underestimated since the early (= pre-diagnosis) phase of central precocious puberty is characterised by an acceleration of height gain that often has a lowering effect on BMI; it is by growing faster that girls can escape from ectopic adiposity.

In conclusion, a vast majority of girls with isolated variants of central precocious puberty were found to have experienced an upward mismatch between prenatal and postnatal weight gain. The clinical data of Harbulot et al. (11) allowed us to infer this simple message which, however, implies that treatment in most girls with precocious puberty should aim not only at silencing the gonadotropic axis but also at reducing weight gain https://eje.bioscientifica.com https://doi.org/10.1530/EJE-21-0287 (c) 2021 The authors Published by Bioscientifica Ltd. Printed in Great Britain

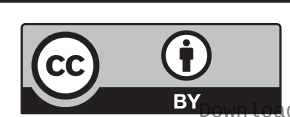

This work is licensed under a Creative Commons Attribution 4.0 International License. 
Mismatch between Prenatal Weight Gain and Postnatal Weight Gain in Girls with Isolated Variants of Central Precocious Puberty ( $N=319$ )

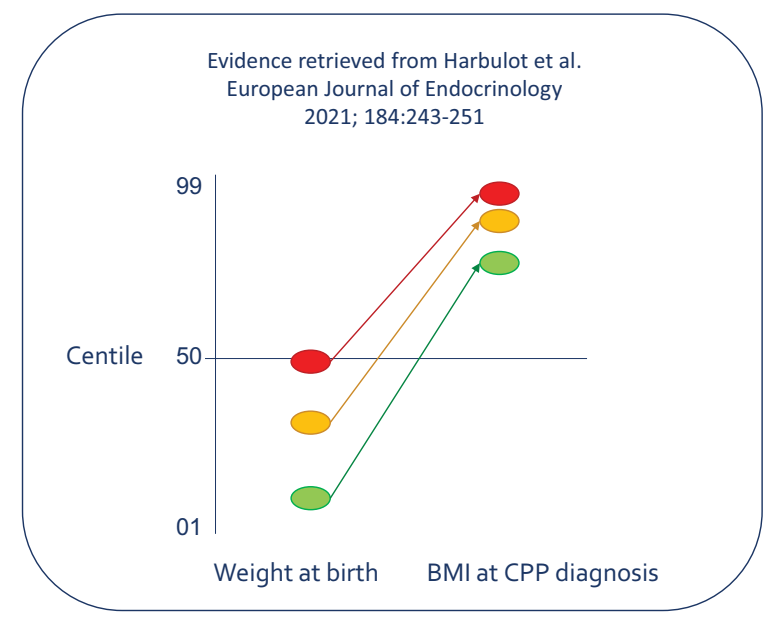

\section{Figure 1}

Mismatch between prenatal weight gain and postnatal weight gain in girls with isolated variants of central precocious puberty (CPP; $n=319$ ). Weight at birth is expressed in centiles for sex and gestational age. BMI at diagnosis of CPP is expressed in centiles for sex and chronological age. The authors of the original paper (11) distinguished three subgroups of girls with isolated CPP. In the 'familial' subgroup (red), the average centile rose from 50 (weight at birth) to 96 (BMI at diagnosis of CPP), for an upward mismatch of 46 centiles. In the 'sporadic' subgroup (orange), the average centile rose from 34 to 90 , for an upward mismatch of 56 centiles. In the 'adopted' subgroup (green), the average centile rose from 10 to 76, for an upward mismatch of 66 centiles.

Marked mismatches are known to be associated with insulin resistance and ectopic fat in girls aged 8 years (10).

and/or ectopic fat. Central precocious puberty in girls should henceforth be viewed as possibly reflecting the activation of the gonadotropic axis in a homeostatic and evolutionarily conserved attempt to escape from ectopic adiposity.

\section{Declaration of interest}

The authors declare that there is no conflict of interest that could be perceived as prejudicing the impartiality of this article.

\section{Funding}

This work did not receive any specific grant from any funding agency in the public, commercial, or not-for-profit sector.

\section{References}

1 Eckert-Lind C, Busch AS, Petersen JH, Biro FM, Butler G, Bräuner EV \& Juul A. Worldwide secular trends in age at pubertal onset assessed by breast development among girls: a systematic review and meta-analysis. JAMA Pediatrics 2020174 e195881. (https://doi. org/10.1001/jamapediatrics.2019.5881)

2 Kim YJ, Kwon A, Jung MK, Kim KE, Suh J, Chae HW, Kim DH, Ha S, Seo GH \& Kim HS. Incidence and prevalence of central precocious puberty in Korea: an epidemiologic study based on a national database. Journal of Pediatrics 2019208 221-228. (https://doi. org/10.1016/j.jpeds.2018.12.022)

3 Jung MK, Choi HS, Suh J, Kwon A, Chae HW, Lee WJ, Yoo EG \& Kim HS. The analysis of endocrine disruptors in patients with central precocious puberty. BMC Pediatrics 201919 323. (https://doi. org/10.1186/s12887-019-1703-4)

4 de Zegher F, López-Bermejo A \& Ibáñez L. Central obesity, faster maturation, and 'PCOS' in girls. Trends in Endocrinology and Metabolism 201829 815-818. (https://doi.org/10.1016/j.tem.2018.09.005)

5 Gluckman PD \& Hanson MA. Living with the past: evolution, development, and patterns of disease. Science 2004305 1733-1736. (https://doi.org/10.1126/science.1095292)

6 Ong YY, Sadananthan SA, Aris IM, Tint MT, Yuan WL, Huang JY, Chan YH, Ng S, Loy SL, Velan SS et al. Mismatch between poor fetal growth and rapid postnatal weight gain in the first 2 years of life is associated with higher blood pressure and insulin resistance without increased adiposity in childhood: the GUSTO cohort study. International Journal of Epidemiology 202049 1591-1603. (https://doi. org/10.1093/ije/dyaa143)

7 Ong KK, Potau N, Petry CJ, Jones R, Ness AR, Honour JW, de Zegher F, Ibáñez L, Dunger DB \& Avon Longitudinal Study of Parents and Children Study Team. Opposing influences of prenatal and postnatal weight gain on adrenarche in normal boys and girls. Journal of Clinical Endocrinology and Metabolism 200489 2647-2651. (https://doi.org/10.1210/jc.2003-031848)

8 Sloboda DM, Hart R, Doherty DA, Pennell CE \& Hickey M. Age at menarche: influences of prenatal and postnatal growth. Journal of Clinical Endocrinology and Metabolism 200792 46-50. (https://doi. org/10.1210/jc.2006-1378)

9 de Zegher F, Reinehr T, Malpique R, Darendeliler F, López-Bermejo A \& Ibáñez L. Reduced prenatal weight gain and/or augmented postnatal weight gain precedes polycystic ovary syndrome in adolescent girls. Obesity 201725 1486-1489. (https://doi.org/10.1002/oby.21935)

10 de Zegher F, Malpique R, Garcia-Beltran C \& Ibáñez L. Towards a simple marker of hepato-visceral adiposity and insulin resistance: the Z-score change from weight-at-birth to BMI-in-childhood. Pediatric Obesity 201914 e12533. (https://doi.org/10.1111/ijpo.12533)

11 Harbulot C, Lessim S, Simon D, Martinerie L, Storey C, Ecosse E, De Roux N, Carel JC \& Léger J. Prevalence and clinical characteristics of isolated forms of central precocious puberty: a cohort study at a single academic center. European Journal of Endocrinology $2021 \mathbf{1 8 4}$ 243-251. (https://doi.org/10.1530/EJE-20-0862)

Received 18 March 2021

Revised version received 5 May 2021

Accepted 5 May 2021 